\title{
EL GUARDIÁN DE MI HERMANO RECURSOS PARA UN GIRO ÉTICO EN PSICOANÁLISIS ${ }^{1}$
}

\author{
Donna M. Orange, Ph.D., Psy.D.² \\ Claremont, CA, USA
}

Los clínicos y otros profesionales que ayudan, trabajan con las personas gravemente traumatizadas, las destruidas por la privación y la violencia temprana o posterior; esto es lo que los clínicos hacen durante toda su vida, sino se agotan y quedan exhaustos. Responsables de los demás, testigos de la atrocidad, vulnerables, incluso como rehenes de los devastados, tenemos que interiorizar y nutrir nuestros recursos, a través un "coro interno", que nuestros maestros y nuestros modelos culturales nos ofrecen.

\section{Palabras clave: Ética, Psicoanálisis, Profesionales de la Salud Mental}

Working with the seriously traumatized, those destroyed by early and later deprivation and violence, as clinicians and other humanitarian workers do throughout their lives, more than exhausts them. Responsible for the other, witnesses to atrocity, vulnerable, even hostage to the devastated, we need to internalize and to nourish the resources, as in an "internal chorus," that our teachers and our cultural models offer us.

Key Words: Ethics, Psychoanalysis, Mental Health Professionals English Title: MY OTHER'S KEEPER. RESOURCES FOR THE ETHICAL TURN IN PSYCHOANALYSIS

\section{Cita bibliográfica / Reference citation:}

Orange, D.M. (2016). El guardián de mi hermano. Recursos para un giro ético en Psicoanálisis. Clínica e Investigación Relacional, 10 (1): 11-26. [ISSN 1988-2939] [Recuperado de www.ceir.info ] DOI: 10.21110/19882939.2016.100101

\footnotetext{
${ }_{1}^{1}$ Traducción castellana de Carlos Rodríguez Sutil. Conferencia leída en Ágora Relacional/Instituto de Psicoterapia Relacional, Madrid, el 15 de Enero de 2016.

${ }^{2}$ Donna M. Orange es Doctora en Filosofía y Psicología, Analista Supervisora del Instituto para el Estudio Psicoanalítico de la Subjetividad (NYC, USA) y profesora del Programa Postdoctoral de la NYU, ISIPSé (Roma) y muchas otras instituciones. Miembro de Honor IPR. Sus obras: Comprensión Emocional. Estudios en Epistemología Psicoanalítica (Guilford, 1995); Mundos de Experiencia: Entretejiendo las Dimensiones Filosófica y Clínica en Psicoanálisis (con Stolorow y Atwood, Basic Books, 2002); Pensar la práctica clínica: Recursos Filosóficos para el Psicoanálisis Contemporáneo y las Psicoterapias Humanistas (2010; Cuatro Vientos, 2012); El Extraño que Sufre: Hermenéutica para la Práctica Clínica Cotidiana (2011); Nourishing the Inner Life of Clinicians and Humanitarians; The ethical turn in Psychoanalysis (Routledge, 2016) y muchas otras publicaciones; Dirección de contacto: 570, Mayflower Road - Claremont, CA 91711 Donna.orange@gmail.com www.donnamorange.net
} 
¿Estás cansado? La mayoría nos damos cuenta de que eso es un eufemismo. Nos podemos sentir asfixiados, como bajo una hipoteca aplastante, cuando trabajamos con pacientes devastados, convencidos de que su deterioro va más allá de toda posibilidad de arreglo, sin esperanza de que los quieran, carentes de valor y buenos para nada, humillados por encima de toda inclusión en la comunidad humana, trabajando con injusticias sociales masivas y crisis climáticas como contexto cotidiano, esforzándonos de forma permanente para recuperarnos de nuestras propias historias traumáticas. No basta. No es suficiente. Yo no soy suficiente. Mis dos libros anteriores, Pensamiento para Clínicos y El Extraño que Sufre, ofrecían algunos recursos a partir de mis tradiciones intelectuales más relevantes - la filosofía y el psicoanálisis - con que describir mis sentimientos en psicoterapia. Estos libros intentaban mostrar una convergencia significativa entre la actitud dialogante y la ética radical posterior al Holocausto, junto con las tendencias al "giro ético" que han surgido recientemente en psicoanálisis. Pero estos libros dejaron al clínico esforzado, incluyendo a su propia autora, en una dolorosa brecha entre las infinitas responsabilidades ante el prójimo sufriente y las demasiado limitadas capacidades humanas del profesional.

Cada libro buscaba responder a un requerimiento de los colegas. El primer libro, Pensamiento para Clínicos (Orange, 2010), atendía a los clínicos que solicitaban ayuda para leer filosofía, utilizando sus conceptos y cuestiones como ayuda en la lectura de la literatura psicoanalítica. El Extraño que Sufre (Orange, 2011) atendía a aquellos que durante muchos años solicitaron un libro sobre hermenéutica, el estudio de la interpretación y la comprensión, para los colegas que trabajan con los que se sienten devastados, cuyo sufrimiento parece estar más allá de todo sentido. Ahora me he topado con otros dos requerimientos.

A menudo los colegas me piden que produzca algo de tipo más personal, incluso una autobiografía. Cierta mezcla de reticencia personal y de sinceridad ética - tentativa al menos - me lo impide. Mi vida no tiene que ver conmigo sino con los demás. $Y$, sin embargo, la biografía nos atormenta: ¿qué parte de destino y qué parte de elección nos ha traído a donde estamos hoy en día? Nacida como católica romana en la costa noroeste del Pacífico, estudié en la Universidad Yeshiva y desde entonces he vivido y trabajado en un mundo predominantemente judío. Tras abrazar la cultura psicoanalítica también aprendí algo de alemán (supuestamente para leer Freud y la filosofía) y contraje matrimonio dentro de una familia germano-americana. Mientras estudiaba sobre el apoyo entusiasta del nacionalsocialismo por parte de los luteranos alemanes, evitaba mirar mucho la complicidad de los católicos y su enérgica participación, algo probablemente peor. De manera parecida evito la biografía y las memorias, esperando 
abordar las obras sobre "duelo y psicología moral" (Lear, 2014), sobre internalización, integración e integridad, mediante una vida de servicio a los demás, intentando vivir con sensatez como guardián de mi hermano.

Por ello no me puedo evadir del segundo requerimiento: ¿qué formas de responsabilidad impregnan a todos los trabajadores humanitarios, incluyendo a los clínicos, y cómo podemos seguir respondiendo? ¿Cuáles son los recursos personales, espirituales y comunitarios que nos nutren mientras intentamos dar respuesta y vivir con humanidad? Intentemos considerar esta cuestión hoy, en un espíritu tan dialogante como sea posible, pero, debo avisar que no hallaremos respuestas generales, sino que al final terminaremos con preguntas que nos afectarán a todos. No existe fórmula que cubra las necesidades de todos.

¿Cómo podemos seguir viviendo - clínicos o trabajadores humanitarios - según una ética que nunca nos autoriza a decir que hemos hecho lo suficiente? Además de una formación seria, profunda, no dogmática, dialogante y que evite los abusos; además de un profundo deseo personal que se cimenta en un sentido de la vocación, así como de la historia relacional; más allá de los actuales recursos intelectuales y sustentadores de nuestras comunidades profesionales. ¿Qué necesitamos para seguir respondiendo, para seguir trabajando con la persona devastada? Dada nuestra vulnerabilidad ante los peligros emocionales del trabajo humanitario, dada nuestra exposición como seres humanos a la enfermedad y al envejecimiento, dadas nuestras limitaciones personales y humanas, dado el carácter de aislamiento de muchas tareas éticas, humanitarias o terapéuticas. ¿Cómo podemos dedicarnos a la curación, a la enseñanza y a restaurar la dignidad de los otros? ¿Cómo puede ser que la práctica de la filosofía (en su sentido antiguo) dé apoyo a un "giro ético" (Baraitser, 2008) en el psicoanálisis contemporáneo? Claire Elise Katz explica que "este giro - que pone al otro por delante - debe convertirse en la condición directriz de nuestras vidas" (Katz, 2013, p. 72). Continúa diciendo que Emmanuel Lévinas:

... describe esta humildad en términos de alguien que no tiene tiempo para observarse a sí mismo. No se trata de "negar" al self-como en el ascetismo, pues el self ya no es lo que interesa. No se trata de elegir entre el yo y el Otro, pues dicha elección ya no es posible. Más bien el yo se ha girado hacia el Otro (pp. 72-73).

Creo que el clínico profesional, o el trabajador humanitario, también el filósofo, pueden internalizar los recursos esenciales necesarios para nutrir y sostener el tipo de práctica que requiere el trabajo clínico en lo mejor de la tradición psicoanalítica, incluyendo el giro ético. Las capacidades y actitudes necesarias implican no sólo sabiduría 
y compasión, sino también vulnerabilidad y capacidad de error, coraje y humildad. Dado que nosotros, clínicos, tenemos debilidades humanas ¿cómo vamos a soportar tanta carga, soledad y ataques? Permítaseme intentar una respuesta parcial a esta cuestión.

Para no enredarme en abstracciones, en mis libros he elegido interlocutores ejemplares, aunque claramente imperfectos. En lugar de hablar de filosofía en general, hablamos con Martin Buber, Hans-Georg Gadamer, Maurice Merleau-Ponty, Ludwig Wittgenstein y Emanuel Lévinas. Para dar a luz a la hermenéutica de la confianza hemos estudiado a D.W. Winnicott, Frieda Fromm-Reichmann, Heinz Kohut y Bernard Brandchaft.

Por el camino, sin embargo, ha ocurrido algo de tipo muy personal, algo a lo que Sandra Buechler, cuando escribe sobre la experiencia de la soledad en el psicoanalista, llama el uso de un "coro interno". Según ella:

El coro interno que llevamos todos los días a nuestras consultas debe ser acogedor y lo suficientemente estimulante como para animar al uso creativo de la soledad. El sentimiento que este coro nos debe transmitir es que pase lo que pase hoy, con este paciente concreto, eso no nos define como analistas pues ya hemos sido definidos y nos hemos definido a nosotros mismos mediante nuestras identificaciones analíticas y la formación de nuestra identidad. No nos la jugamos personal y profesionalmente con cada nueva interacción con un paciente. (p.111)

De esta forma mi coro interno me mantiene estable y respondiendo ante el otro, incluso cuando me siento asediada, perseguida y exhausta o, siguiendo las palabras de Winnicott (1975), en riesgo de tomar represalias (in danger of retaliating) (Winnicott \& Institute of Psycho-analysis (Great Britain), 1975). Cuando fracasamos, como me ha ocurrido muchas veces, o cuando perdemos un paciente por razones que sólo conocemos en parte, mi coro me ayuda a retomar mi trabajo sin recriminármelo tanto como haría si no tuviera esas voces. De la misma forma los trabajadores humanitarios persisten ante el hambre, la enfermedad y la violencia. Buechler sigue diciendo:

Sobre esta base podemos experimentar la soledad con un paciente como un elemento de información, más que como un juicio. Podemos darle vueltas a la soledad en nuestra cabeza, preguntarnos de qué se trata, sentir curiosidad por ella, considerarla significativa, como algo que hay que entender y no como un obstáculo o una acusación. Una soledad que no nos prive de una buena conexión con nosotros mismos, con nuestro coro o con el paciente, puede ser utilizada con creatividad. (p. 111) 
Mis filósofos y psicoanalistas favoritos son miembros indispensables de mi coro interno ${ }^{1}$, que puedo convocar cuando es necesario. Me hablan, juntos y por separado, tanto para lanzarme reproches como para ponerme sobre aviso - como el daimon de Sócrates - y como el coro de apoyo de Sandra Buechler, que me recuerdan que mi auténtico ser no está en juego en cada sesión. Mis cantores actuales me proporcionan la experiencia adicional, no particularmente cómoda o reconfortante, de ser "lector por mandato", como dice Jonathan Lear (2012, p. 169), de las responsabilidades "infinitamente demandantes" (Simon Critchley, 2007). Mi coro incluye también personas cuyos nombres pocos reconocerían: mis mejores profesores que me ayudaron a imaginar que las mujeres podían llegar al liderazgo pero sin tener nunca un "nombre" propio, mi analista didacta y dos de mis primeros supervisores que creyeron en mí mucho antes de que yo tuviera una idea de mis propias capacidades, muchos artesanos poco pretenciosos, ajenos a los ambientes clínicos o humanitarios, que trabajaban con fuerza y fidelidad en cualquier cosa que hacían.

Cada uno reunimos como podemos nuestros recursos sustentadores: mediante la meditación, la imitación, a través de diversas formas de viaje espiritual. Para mí, probablemente por la disciplina aprendida cuando era joven, en mis años en el convento, mi mejor camino se desarrolla a través de un periodo de lectura meditativa, mantenida cada día y a hora temprana antes de que otras preocupaciones lo invadan. Todos los autores que aparecen en este libro, y alguno de los dos anteriores, pueden ser leídos como objeto de estudio, como un interlocutor dialogante, o como un guía espiritual. Todos ellos ayudan a formar esa voz ética interna que Sócrates llamó su daimon, manteniéndome preparada ante el rostro y la voz del extraño ante el cual voy a ser llamada a responder.

Buechler (1998) recurre a la imagen del corredor de fondo. Recuerdo que en mis años jóvenes de maratoniana necesitaba tanto coger mi ritmo como encontrar los recursos internos y externos que me permitieran seguir la marcha. Para mí la idea y la realidad del coro interno sigue en evolución. Algunos integrantes pasan a un segundo plano mientras que otros ganan prominencia y llegan nuevas voces que me inspiran y desafían. Incluso durante la redacción de mi último libro se han producido algunos desplazamientos, cuando descubrí noticias decepcionantes de algunas figuras que había admirado durante mucho tiempo, mientras que a otras las he llegado a conocer y a apreciar más. Algunas proceden de mi ambiente profesional y otras de una esfera cultural más amplia, como sospecho que les ocurre a psicoterapeutas y trabajadores humanitarios de todas las orientaciones. 
Recientemente he prestado especial atención a algunos miembros del coro procedentes de fuera del mundo de la práctica de la psicoterapia en la tradición psicoanalítica. Entran en conversación unos con otros y a menudo me sorprenden. Se han convertido en personajes de mi diálogo interior, como si de una obra de ficción se tratara. Pero sospecho que tú, que te implicas en tu propio coro interno dialogante, también encontrarás sostenimiento y revelaciones. "Conócete a ti mismo", exhortaban los antiguos griegos. Conocer de manera más íntima a aquellos que nos influyen, y cuyas voces nos alimentan y dan sustento - no sólo los denominados "malos objetos" - pueden ayudarnos a mantener una respuesta ética. De no ser así, nuestro trabajo se vuelve simplemente demasiado duro y solitario.

En primer lugar, sin embargo, ¿por qué es tan solitario nuestro trabajo? ¿y por qué necesitamos tanto esta ayuda? Seguramente sus orígenes traumáticos son los que vuelven nuestro trabajo tan exigente, en medio de la situación de un "mundo que arde" (Cushman, 2007; Richardson y Zeddies, 2004). Si nos apoyamos en obras recientes sobre el testimonio y la realización, queda claro por qué trabajar con pacientes gravemente traumatizados es tan exigente para el clínico, lo que requiere que este tipo de recursos corales internos sean nutridos y repuestos de forma continua. Sin hacer una revisión amplia de la literatura académica y científica sobre el trauma, consideramos que el trauma, junto con la condición de "traumatismo" que evoca al reclamar una respuesta ética, pone más en claro por qué dichos recursos personales, comunitarios y espirituales se vuelven indispensables para los trabajadores clínicos y humanitarios. ${ }^{2}$

Demos por supuesto que el trauma es tanto un acontecimiento como una experiencia. Algo terrible ha ocurrido: un terremoto, una violación, la muerte de un niño, tortura, genocidio, un diagnóstico de cáncer. Nada puede ser como era antes, ni podemos confiar en que sea como asumíamos que era. Tu mundo acaba de ser trastornado (Stolorow, 2007), e incluso cuando poco a poco se va reorganizando en torno a la devastación del tornado o los dictados del dictador, esta realidad está siempre amenazada por la sensación de que pueden ocurrir cosas terribles en cualquier momento. El testigo psicoanalítico, como ha escrito Warren Poland de forma tan clara y elocuente, es aquel que lo capta 3 y de esa forma permite que el paciente lo capte, de la misma forma que mi pregunta a mi asesor informático desencadenó su propia experiencia traumática (Poland, 2000).

Pero quien responde, sin egoísmo, puede estar también traumatizado. "¿Qué puede querer decir esto - pregunta Simon Critchley (1999) - pensar en el significado del 
inconsciente en términos de un traumatismo persecutorio? ¿Qué significa pensar en el sujeto - el sujeto del inconsciente - como trauma?" (p. 188).

Destaca en la descripción de Poland, algo que es recogido en el comentario de Alfred Margulies (Margulies, 2000), el cambio que se produce entre reaccionar ante el paciente y el responder ante el otro. Margulies escribe: "Al aflojar el cepo de una hermenéutica de la sospecha, Poland se está desplazando de un intento por entender a alguien a intentar estar con el otro" (p. 76). Corregiría la formulación de Margulies de forma leve pero quizá importante: Poland se encuentra a sí mismo al lado del otro. Esto puede ser la consecuencia de un cambio de actitud más fundamental del que él ya ha hecho: a menudo habla de trabajar al servicio del paciente. ¿Pero qué hay del "trauma" y la "persecución"?

El clínico, como los otros trabajadores humanitarios, vive en una doble asimetría. Desde un punto de vista superficial todos tenemos capacidad para la relación clínica. Encuadramos el tiempo, el lugar, el precio, y decidimos si vamos a ver a esta persona trastornada o no. Por otra parte, cuando estamos implicados nos sentimos asediados y perseguidos por el rostro del Otro, justo como Lévinas escribió. Una expresión que utilizó para esta condición de responsabilidad infinita, cuando somos tan finitos, fue la de traumatismo4. Critchley explica que para Lévinas "mi relación con el otro no es una benigna benevolencia, un cuidado compasivo o el respeto por la autonomía del otro, sino una experiencia obsesiva de responsabilidad que me persigue con su enorme peso" (Simon Critchley, 2007, pp. 60-61). "La demanda ética - sigue diciendo Critchley - es una demanda traumática, es algo que viene de fuera del sujeto, de una fuente heterónoma, pero que deja su marca dentro del sujeto" (p. 61). La condición del sujeto perseguido por una responsabilidad pre-original es que el traumatismo nunca acaba. Escuchamos a Lévinas, desde luego, bajo dos registros, el del insomne 5 para quien los asesinatos nunca terminan ni los muertos regresan, y como el filósofo de la subjetividad previa y más allá del yo.

Es desde la subjetividad entendida como un self, desde... la desposesión del encogimiento, por la que el Ego no aparece sino que se inmola a sí mismo, que la relación con el otro es posible como comunicación y trascendencia (Lévinas, Peperzak, Critchley, \& Bernasconi, 1996, p 92).

El sujeto de Lévinas, lejos de ser un ego expansivo o agente ${ }^{6}$, está sometido, más pasivo que toda pasividad, perseguido, secuestrado, es responsable del otro según un traumatismo pre-original. Esta capacidad receptiva del sujeto hace posible su relación con el otro como una comunicación y trascendencia "en el lado del prójimo"7, antes de 
que nada pueda ser dicho. El sujeto se constituye como sujeto en un "traumatismo original", como sujeto de persecución y sufrimiento. En palabras de Simon Critchley: "Concibe el sujeto como un trauma - la ética es un traumatismo" (1997, p. 231).

A continuación consideramos el "giro ético" en sus dos fuentes: filosófica y psicoanalítica. La parte filosófica puede ser remitida al "giro" de Derrida en sus últimos años, una vez que asimiló lo que Lévinas estaba diciendo. La parte psicoanalítica se refiere también a los componentes del psicoanálisis relacional que se orientan hacia la justicia social, y a los que como nosotros escribimos siguiendo una inspiración levinasiana. Todos los congresos La Psicología y el Otro (véase su website, tienen lugar cada dos años, y esta ya es la tercera edición) expresan realmente las sensibilidades interdisciplinarias a las que yo denominaría "el giro ético". Wittgenstein podría decir que los usos del término tienen parecidos de familia.

En cualquier caso, se trata de un rechazo de la "Kehre" de Heidegger porque pertenece profundamente al mundo actual. (Precisamente ahora estoy escribiendo algo sobre en qué medida el giro ético necesita despertar ante la crisis climática). Yo crecí en la filosofía durante el llamado "giro lingüístico", tal como se entendía en los círculos angloamericanos, que a muchos nos expulsó de la filosofía. Ahora reclamamos lo ético, de vuelta a Sócrates, como el dominio esencial de la filosofía, y nos preguntamos si no será también el dominio fundacional para el psicoanálisis. Observamos, por ejemplo, la ética evolutiva de la responsabilidad personal, en el psicoanálisis de Hans Loewald, y nos cuestionamos sobre qué añadiría una ética de la hospitalidad (Orange, 2012), de la generosidad clínica (Butler, 2004; Corpt, 2009), de la vulnerabilidad (Aron y Starr, 2012; Butler, 2004), con las que muchos de nosotros hemos estado intentando confrontar tanto el elitismo del psicoanálisis tradicional como la indiferencia ante el sufrimiento de la gente a la que parecemos incapaces de ver y oír, o de permitirle que nos moleste. Algunos preguntarán ¿por qué tengo que sentirme culpable todo el tiempo? Bueno, todo depende de lo que queramos decir con "culpable" y con "ética".

Pero esta cuestión explota en la conversación tan pronto como menciono las ideas éticas de Dostoyevski (Soy culpable/responsable de todo y ante todo) y Lévinas. ¿No es del masoquismo moral de Freud de lo que están hablando? ¿Poniendo al otro delante, no me pierdo a mí mismo? ¿No estamos intentando ayudar a nuestros pacientes a superar dicha carencia de self? Históricamente, el masoquismo es el deseo inconsciente de sufrir por los propios pecados del deseo edípico. Con el giro ético consideramos la constitución del sujeto ético, no como alguien que quiere sufrir sino como alguien dispuesto a ello cuando se enfrenta al sufrimiento de los otros. Creo que la rendición-cesión (surrender), 
según Emmanuel Ghent, ante la tarea ética no equivale a una sumisión automática, a un falso self, sino a lo que Winnicott denominó "nada menos que todo". No es algo trivial. La vida ética se efectúa mediante el sometimiento al otro. Respondemos a la pregunta de Caín: "Sí, yo soy el guardián de mi hermano".

Para comenzar a dar ejemplos sobre el "coro interno" recurro a Pierre Hadot, historiador de filosofía antigua, quien mostró con nitidez que para Sócrates, Platón, los estoicos y los epicúreos, la filosofía era primariamente un modo de vida terapéutico, practicado dentro de una comunidad de amantes del saber, entre otras, cuyas teorías éticas buscaban dar apoyo al camino que cada grupo había elegido. Los libros de Hadot han pasado a ser compañeros cotidianos de mi coro. Junto con A.A. Long (2002), quien me enseñó a leer a Epícteto, Hadot me abrió a la idea de que se puede vivir cada día para la comunidad humana sin preocuparse mucho por los resultados. Saber que somos una pequeña parte del universo, percatarnos de que continuamente nos estamos preparando para morir, diferenciar entre aquello que nos pertenece (nuestras elecciones y actitudes) y lo que no (la fama, el dinero, las elecciones y opiniones de los otros, incluso la salud) nos libera de muchas preocupaciones. Marco Aurelio, el favorito de Hadot, que enseñó precisamente estas actitudes, ha sido mi compañero permanente en momentos de aflicción. Hadot nos recuerda, citando a George Friedmann, que cuidar de nuestro espíritu no es egocéntrico o egoísta:

¡Emprende el vuelo cada día! Al menos por un momento, que sea intenso aunque breve. Un "ejercicio espiritual" cada jornada, ya sea solo o en compañía de alguien que desee mejorarse a sí mismo. Ejercicios espirituales. Salirse del tiempo... Intenta dominar tus pasiones, vanidades y el impulso de hablar en tu propio nombre, que a veces te quema como si fuera una enfermedad crónica. No extiendas rumores. Libérate de la lástima y el odio. Ama a todos los seres humanos libres. Conviértete en eterno trascendiéndote a ti mismo.

Este trabajo sobre ti mismo es necesario. Esta ambición, justificada. Muchas personas se prestan a ser absorbidas por la política militante y los preparativos de la revolución social. Raros, mucho más raros son aquellos que, para preparar la revolución, están dispuestos a hacerse merecedores de ella.

Vayamos ahora directamente al infierno. El joven químico turinés, Primo Levi, decidido a que la experiencia inmediata de aquellos "hundidos y salvados" en Auschwitz fuera contada y conocida, comenzó escribiendo su detallado "cuento de terror" a la hora de las comidas, tan pronto como fue capaz de volver al trabajo después de la liberación. Su insistente voz sobre la dignidad humana, siempre rechazando el error y la evasión y 
que, finalmente, le costó la vida, me desafía y atormenta. Concuerda con las de Dostoyevski y de Emmanuel Lévinas, que insisten en que nunca debemos permanecer indiferentes a la muerte del otro.

Otros integrantes recientes del coro han sido Nelson Mandela y Dietrich Bonhoeffer. Bonhoeffer, un pastor cristiano que desde muy joven parece haber entendido la no indiferencia ante el destino del otro y que la vivió hasta el final, que fue encarcelado y ahorcado por tomar parte en el complot para asesinar a Hitler. Su sentido de la comunidad como algo esencial para la vida ética o religiosa le hizo aún más difícil soportar años de aislamiento en prisión. Mandela, un revolucionario que se convirtió en un símbolo mundial de la tranquila dignidad humana, permaneció en prisión durante veintisiete años antes que comprometer la total igualdad de su pueblo. Tanto Nelson Mandela como Dietrich Bonhoeffer, al igual que Pierre Hadot, entendieron la filosofía como una forma de vida. Todos ellos lograron hacer "ejercicios espirituales" en prisión todos los días y el desarrollo personal en servicio de la comunidad humana.

La Rusia de Dostoyevski junto con los textos del judaísmo y la fenomenología constituyeron la primera de las tres grandes influencias en la ética de Emmanuel Lévinas. Acabo de regresar a la gran obra maestra, Los Hermanos Karamazof, no con la profundidad que indudablemente merece, por lo que contribuye a mi coro. Se organiza en torno de la infame pregunta de Caín. (Desde luego, todo clínico o trabajador humanitario debe encontrar, reclutar y organizar su propio coro. Nadie puede adoptar el mío. Pero como figura literaria relacionada se puede elegir a Dickens, el novelista inglés favorito de Dostoyevski, por su parecida sensibilidad ética y capacidad narrativa. O quizá Victor Hugo). El amor de por vida de Dostoievski hacia los más desfavorecidos, su interminable pelea contra toda forma de egoísmo filosófico, junto con su mantra: Soy culpable / responsable de todo y ante todo, y yo más que nadie; inspira incluso ahora una ética de la responsabilidad por el otro.

Tras haber permitido que todas estas voces convergieran en mí en mis sesenta, comienzo mis setenta meditando sobre la profecía y la humildad, en especial la humildad clínica. Desde los profetas hebreos a través de muchos de los textos que he leído aquí hasta la fenomenología profética de Emmanuel Lévinas, he aprendido a entender el trabajo clínico y humanitario como una palabra profética en acción. Una vez oída dicha palabra profética no hay escape posible, sólo intentar escuchar mejor, para responder incluso antes de haberlo oído todo. Pero como la invocación viene del infinito hasta mi yo finito, la vulnerabilidad y el error continuo requieren muchas formas de humildad o de rendición-cesión ante la falibilidad, el envejecimiento y el otro. La autenticidad, la 
autodefinición y mi lugar bajo el sol dejan de ser importantes. En lugar de ello, con discreción, viene una vida vivida para el otro.

Ya habréis percibido que esta historia tiene un reparto más personal que mis obras anteriores: estos miembros del coro son mi gente especial. Tienen defectos graves, como yo: Dostoyevski era ludópata y antisemita (esto no le impidió a Lévinas adorar su obra). La actitud de Bonhoeffer hacia la mujer y el matrimonio era, en mi opinión, antediluviana; y aunque murió como consecuencia de sus esfuerzos por parar el Holocausto, seguía pensando que los judíos eran cristianos subdesarrollados. El coraje y la habilidad política de Mandela superaron, según se dice, lo que fue su trato de la familia. Lévinas pensaba que Europa era el centro del universo y en sus teorías hizo un uso problemático de los conceptos de género. Como ellos yo tengo prejuicios que sólo los otros pueden ver, aunque sigo tratando de mejorar mi percepción escuchando con un segundo oído y leyendo a mis críticos.

Mi amor por los idiomas probablemente me ha permitido sintonizar con algunos miembros de mi coro: con el italiano de Primo Levi, con el francés de Lévinas, MerleauPonty y Hadot, con el alemán de Freud, Gadamer, Wittgenstein, Bonhoeffer, Loewald y Bach. Casi antes de que yo pudiera hablar inglés escuchaba el latín de iglesia que me volvía con el canto gregoriano y con la música de $\mathrm{Bach}^{8}$.

Sólo recientemente me ha impresionado que el incidente central y más impresionante en el libro de testimonio de Levi, Si Esto es un Hombre, ocurre cuando su compañero francés en Auschwitz le pidió que le enseñara italiano, y Levi empezó a explicarle a Dante. Un joven francés, Jean, conocido como Pikolo por el mando, había sido designado para recorrer cada día una hora de distancia y traer la sopa del mediodía para los prisioneros. Durante unos pocos días, que se encargó a Levi que le ayudara, aprovechó este la oportunidad de tener conversación y un trabajo más ligero. Jean quería aprender italiano, así que Levi, a quien se había obligado de niño a aprender gran parte de la Comedia de Dante, comenzó un día a recitar el Canto Veintiséis del Infierno, la historia de cuando Ulises vuelve a casa, explicándolo en francés e italiano a su joven compañero. De pronto declamó las siguientes palabras:

Considerate la vostra semenza:

Fatti non foste a viver come bruti,

Ma per seguir virtute e conoscenza. 
Considerar cuál es vuestra progenie:

hechos no estáis a vivir como brutos, mas para conseguir virtud y ciencia

(Ulises en el Infierno de Dante, Canto XXVI, traducción de Bartolomé Mitre)

"Como si lo estuviera oyendo por primera vez: como un estallido de trompeta, como la voz de Dios. En ese momento me olvidé de quién era y de dónde estaba" (p.113).

Esta impresionante historia nos podría ocupar todo el día; la cuestión aquí es que para mí los idiomas, y mi fascinación con ellos, han sido un continuo recurso interno. Las lenguas nos unen no sólo a los demás, sino también a su propia alteridad. Estudiar idiomas disminuye continuamente en mí el sentido de cualquier resto de egocentrismo. Vosotros encontraréis otras reservas igualmente sustentadoras.

Mi tema unificador es la ética, no la ética de contrato social que considera una diversidad de individuos independientes que negocian derechos, deberes y propiedades, sino la radical ética pre-primordial de la responsabilidad infinita ante la otra persona (Lévinas, 1979, 1998). Los clínicos y trabajadores humanitarios necesitan un apoyo interno y externo porque su tarea demanda una respuesta ética valiente cada día, y nunca cesa. Para una vida más fácil esto sería irrelevante, una pérdida de tiempo, o al menos no tan indispensable.

Ahora más que antes, desde la perspectiva del envejecimiento, mi tarea se dirige a los clínicos jóvenes y a los que están a mitad de camino. Situándonos en el lenguaje psicoanalítico más familiar, esto se refiere a internalizar las voces y el ejemplo de aquellos que necesitamos mantener si queremos continuar nuestra tarea muchos años. Os permite conocer algunos de aquellos que, durante los últimos años, he admirado con mayor intensidad. Todas estas personas, repito, tienen grandes defectos. Todos sufrieron desazones. Uno se suicidó, otro se ahorcó. La mayoría pasaron mucho tiempo en prisión o en campos de internamiento, y todos sufrieron numerosas e importantes pérdidas personales. No obstante, todos lograron realizar alguna contribución significativa a la cultura humana, y sus voces se han entrelazado para darme apoyo de una forma que describiré si el tiempo lo permite. La mayoría también me causaron un importante malestar. En concreto, me cargaron con el problema de mi amor por las riquezas de la cultura europea - en particular, la cultura alemana - la sede de la más calculada masacre de otro pueblo que registra la historia, pueblo con el que he llegado también a sentirme profundamente identificada. Por tanto, los miembros de mi coro me apoyan y consuelan, pero también me inquietan. 
Como explicaré en mi trabajo sobre la humildad clínica, mis mentores no me impusieron la obligación de sobrevivir de un modo particular, o incluso de sobrevivir. Colocarlos juntos, en verdad, ha constituido una experiencia de humildad: al llegar a aprender tanto que a algunos que me influyeron los había subestimado y sobrevalorado a otros, como es el caso de Bonhoeffer. Como escribe Simon Critchley: "La elaboración de un libro es como el crecimiento de un cáncer, en el que una célula se aparta de su metabolismo habitual, conectando con otras células e infectándolas, interconectando para formar las frases de una página" (Critchley, 1999, p. 33). Esta oscura metáfora describe a mi entender el surgimiento progresivo de una compleja acusación ética, una infección y una persecución que encontrarán entretejidas en las páginas de mi nuevo libro, un síndrome que no fui capaz de ver cuando lo compuse. Lo que yo he escuchado claramente de todos los integrantes de mi coro es la responsabilidad de vivir para los demás, no para mí misma. Irónicamente, su insistente convicción me sostiene.

Aunque el "coro interno" de Sandra Buechler inspira esta nueva obra, aquellos que he leído en busca de apoyo no siempre proporcionan consuelo, como Franz Kafka escribió a su amigo Oskar Pollak:

Creo que sólo debemos leer libros que nos muerdan y piquen. Si el libro que estamos leyendo no nos remueve como un golpe en el cráneo, para qué molestarnos en leerlo primero... lo que necesitamos son libros que nos peguen casi como una desgracia dolorosa, como la muerte de alguien que amamos más que a nosotros mismos, que nos haga sentir como si se nos hubiera expulsado a los bosques, lejos de cualquier presencia humana, como un suicidio. Un libro debe ser el hacha para el mar congelado de nuestro interior... (en Malone, 2003, pp. 117118).

Aunque mi estética es menos austera que la de Kafka, y quizá la vuestra también lo sea, encontraréis algunos recursos - vuestros y míos - más desafiantes que consoladores pero, aun así, espero, que servirán de sustento para vuestro núcleo ético.

Por encima de todo, espero iniciar una conversación entre colegas jóvenes sobre vuestros recursos intelectuales, culturales y espirituales. Además de los primeros maestros, además del cuidado físico, los hobbies, la familia y las amistades bien mantenidas, además del continuado crecimiento profesional, todos los clínicos, según creo, necesitan encontrar a lo largo del tiempo sus personales voces internas, personas vivas y muertas que inspiran y aconsejan y sostienen en momentos de apuros. Este coro cambiará con el tiempo, según se vayan desdibujando las influencias y surgiendo otras nuevas, pero no debe ser desatendido. 
El mío proporciona ejemplos que se han vuelto importantes para mí en los últimos años, aunque algunos han durado mucho tiempo. Los que se han tratado aquí no son las voces formativas; muchas de ellas fueron las mujeres significativas en mis años de educación y formación académica9 ${ }^{9}$. Otras funcionan como aquello que los músicos del Barroco llamaban bajo continuo: acompañan todas mis conversaciones internas. Ejemplos de este tipo incluyen a Sócrates, quien argumentaba que era mejor sufrir que hacer el mal, y que la muerte no supone una amenaza para un buen ser humano. $Y$, no importa lo que la gente religiosa haya podido hacer con él, el Jesús del Sermón de la Montaña, predicando: "Bienaventurados los pobres, los que lloran y los que sufren persecución por la justicia".

Esta precisa conversación, sin embargo, podría convertirse en un recurso fuera de la usual charla de mercado, ya sea clínica o teórica, que compone el material de nuestras conferencias. Incluso podríamos llegar a ser unos los miembros de los coros de otros.

\section{REFERENCIAS}

Aron, L., \& Starr, K. (2012). A psychotherapy for the people: toward a progressive psychoanalysis. Hove, East Sussex; New York, NY: Routledge.

Baraitser, L. (2008). Mum's the Word: Intersubjectivity, Alterity, and the Maternal Subject. Studies in Gender and Sexuality, 9, 86-110.

Buechler, S. (1998). The Analyst's Experience of Loneliness. Contemp. Psychoanal., 34(1), 91-113.

Bokanowski, T. (2005). Variations on the concept of traumatism: Traumatism, traumatic, trauma . Int J Psychoanal, 86, 251-265.

Butler, J. (2004). Precarious life : the powers of mourning and violence. London: New York: Verso.

Corpt, E. (2009). The importance of analytic generosity in the treatment of intergenerational trauma. Paper presented at the Conference on Intergenerational Trauma, Dublin/London.

Critchley, S. (1997). The Original Traumatism: Levinas and Psychoanalysis. In R. Kearney \& M. Dooley (Eds.), Questioning Ethics: Contemporary Debates in Philosophy (pp. 230-242). London: Routledge.

Critchley, S. (1999). Ethics--Politics--Subjectivity: Essays on Derrida, levinas and Contemporary French Thought. London: Verso.

Critchley, S. (2007). Infinitely demanding : ethics of commitment, politics of resistance. London: New York: Verso.

Cushman, P. (2007). A Burning World, an Absent God: Midrash, Hermeneutics, and Relational Psychoanalysis. Contemp. Psychoanal. Contemp. Psychoanal., 43, 47-88.

Frank, A. (2004). The renewal of generosity illness, medicine, and how to live Retrieved from http://www.columbia.edu/cgi-bin/cul/resolve?clio10417432 
Gardiner, J. (2013). Bach: music in the castle of heaven (First United States edition. ed.). New York: Alfred A. Knopf.

Katz, C. (2013). Levinas and the crisis of humanism. Bloomington: Indiana University Press.

Lear, J. (2012). The thought of Hans W. Loewald. Int. J. Psycho-Anal., 93:167-179. International Journal of Psycho-Analysis, 93, 167-179.

Lear, J. (2014). Mourning and Moral Psychology. Psychoanalytic Psychology, 31, 470-481.

Levinas, E. (1979). Totality and infinity: an essay on exteriority. The Hague ; Boston, Hingham, MA: M. Nijhoff Publishers; distribution for the U.S. and Canada, Kluwer Boston.

Levinas, E. (1981). Otherwise than being: or, Beyond essence. Hague; Boston Hingham, MA: M. Nijhoff; Distributors for the U.S. and Canada, Kluwer Boston.

Lévinas, E. (1998). Otherwise than being, or, Beyond essence. Pittsburgh, Pa.: Duquesne University Press.

Lévinas, E., Peperzak, A. T., Critchley, S., \& Bernasconi, R. (1996). Emmanuel Levinas : basic philosophical writings. Bloomington: Indiana University Press.

Loewald, H. W. (1951). Ego and Reality. Int. J. Psycho-Anal., 32, 10-18.

Loewald, H. (2000). The essential Loewald : collected papers and monographs. Hagerstown, Md.: University Pub. Group.

Long, A. A. (2002). Epictetus: a Stoic and Socratic guide to life. Oxford \& New York: Clarendon Press; Oxford University Press.

Malone, N. (2003). Walking a literary labyrinth: a spirituality of reading. New York: Riverhead Books.

Margulies, A. (2000). Commentary. J. Amer. Psychoanal. Assn., 48(1), 72-79.

Orange, D. (2012). "Clinical Hospitality: Welcoming the Face of the Devastated Other" (keynote address). Paper presented at the New Zealand Association of Psychotherapy.

Orange, D. (2002). There Is No Outside. Psychoanal. Psychol., 19(4), 686-700.

Orange, D. (2010). Thinking for clinicians: philosophical resources for contemporary psychoanalysis and the humanistic psychotherapies. New York: Routledge. [v. castellana: Pensar la práctica clínica: Recursos Filosóficos para el Psicoanálisis Contemporáneo y las Psicoterapias Humanistas, Santiago de Chile: Cuatro Vientos, 2012]

Orange, D. (2011). The suffering stranger: hermeneutics for everyday clinical practice. New York: Routledge/Taylor \& Francis Group. [V. castellana: El desconocido que sufre. Santiago de Chile: Cuatro Vientos, 2013]

Poland, W. S. (2000). The Analyst's Witnessing and Otherness. J. Amer. Psychoanal. Assn., 48(1), 17-34.

Richardson, F., \& Zeddies, T. (2004). Psychoanalysis and the Good Life. Contemp. Psychoanal., 40, 617-657. 
Stolorow, R. D. (2007). Trauma and human existence : autobiographical, psychoanalytic, and philosophical reflections. New York: Analytic Press.

Winnicott, D. (1975). Through paediatrics to psycho-analysis. London: Hogarth Press and the Institute of Psycho-Analysis.

Original recibido con fecha: 29/11/2015 Revisado: 15/01/2016 Aceptado: 28/02/2016

NOTAS:

${ }^{1}$ Los lectores familiarizados con mi anterior resistencia al dualismo (Orange, 2002) pueden sorprenderse por el lenguaje de la vida interior, la internalización, y el coro interior. La internalización proporciona la clave, por la cual lo que ha sido externo se convierte en propiedad personal, como si se llevara por ahí de forma interna, algo disponible y sustentador en momentos de angustia. La internalización, entendida psicoanalíticamente (Loewald, 2000), explica el desarrollo de una vida espiritual que verdaderamente no está ni dentro ni fuera, sino en ambos lados.

${ }^{2}$ La Renovación de la Generosidad, de Frank (2004) proporciona de forma semejante recursos filosóficos y éticos tanto para los pacientes como para los trabajadores sanitarios que se enfrentan con un sufrimiento extremo y prolongado.

3 (N.de.T.) "gets it": lo capta, lo atrapa.

4 Tengo una gran deuda con el magnífico ensayo de Simon Critchley (1997) que parece haberse ocupado en profundidad sólo de la cuestión de lo traumático en Lévinas y de su tratamiento del psicoanálisis [¿de quién?]. Un ensayo psicoanalítico (Bokanowski, 2005) utiliza la palabra "traumatismo", pero de manera muy diferente, para referirse sólo a "un nivel de desorganización que tiene más que ver con los procesos secundarios - que no altera las relaciones de objeto y la ligazón de las pulsiones instintivas" (p. 252). El trauma, para este autor, es la condición mucho más grave.

${ }^{5}$ Comenzó a escribir sobre el insomnio durante sus años en un campo de trabajo nazi; no sé si él era un insomne, literalmente, después de la guerra.

${ }^{6}$ Desde luego, existen otras formas de entender al ego freudiano, p.ej., como el emergente relacionado con el individuo que se encuentra en Loewald (1951), pero parece que Lévinas no lo conocía.

7 (N. del T.) La autora dice "on the hither side" (en el lado más cercano) y juega con la semejanza con "on the other side" (en el lado del otro).

${ }^{8}$ Johann Sebastian Bach merece un capítulo de este libro (Orange, 2016). Compositor y director de coro, supera mi capacidad para describir tanto sus logros como la influencia que tiene en mí. Su retrato está colgado en mi estudio, como viejo compositor de la Pasión según San Mateo y la Misa en Si Menor. El director John Eliot Gardiner (Gardiner, 2013) ha estado muy cerca de capturar su espíritu para mí.

9 Desgraciadamente, como en mis dos últimos libros, la mayoría de mis interlocutores más prominentes aquí serán varones, con una pérdida subsecuente por la que pido disculpas anticipadas ante mis lectores. Si la disparidad entre mis fuertes vínculos personales con mujeres colegas y mi uso predominante de recursos intelectuales y culturales masculinos tiene un significado concreto, lo desconozco. Un contraejemplo cada vez más importante es la tremenda, si bien no pretenciosa, voz de Judith Lewis Herman, pionera dedicada a la restauración de la dignidad humana de aquellos que han sido destrozados por violaciones de los derechos humanos, como es el abuso sexual. 